\title{
Lung volume recovery and improvement of pulmonary hypertension following surgical repair for Bochdalek hernia
}

\author{
Manabu Suzuki @ , Takashi Katsuno, Kazuki Kawajiri, Masayuki Hojo
}

Department of Respiratory Medicine, National Center for Global Health and Medicine Hospital, Shinjuku-ku, Japan

\section{Correspondence to} Dr Manabu Suzuki; manabu@nms.ac.jp

Accepted 26 July 2021

Check for updates

(c) BMJ Publishing Group Limited 2021. No commercial re-use. See rights and permissions. Published by BMJ.

To cite: Suzuki M, Katsuno T, Kawajiri K, et al. BMJ Case

Rep 2021;14:e243952.

doi:10.1136/bcr-2021-

243952

\section{DESCRIPTION}

This case presents a 47-year-old woman who underwent Bochdalek hernia repair. The patient was diagnosed with a Bochdalek hernia when she was 35 , but she did not present with any significant symptoms. After two deliveries, weight gain, and sleep apnea, her condition progressed and became complicated. At age 45, she experienced severe cardiopulmonary depression, such as congestive heart failure, secondary pulmonary hypertension and hypoxia with hypercapnia, due to progressive compression of the lung by the Bochdalek hernia (figure 1A).

Although surgical repair is commonly recommended in related cases to prevent complications, surgical repair was not indicated in this patient owing to a high potential for severe complications. After intensive treatment, including oxygen supplementation, non-invasive ventilation and medications, her condition improved.

Before treatment, her mean pulmonary arterial pressure (PAP) and pulmonary vascular resistance (PVR) were $53 \mathrm{~mm} \mathrm{Hg}$ at rest and 3.6 Wood units, respectively. The arterial blood gas analysis showed $\mathrm{pH} 7.35, \mathrm{PCO}_{2} 60.9 \mathrm{~mm} \mathrm{Hg}, \mathrm{PO}_{2} 52.5 \mathrm{~mm} \mathrm{Hg}$, and $\mathrm{HCO}_{3} 34.0 \mathrm{mEg} / \mathrm{L}$.

Following 3 months of treatment, her condition improved, and the mean PAP and PVR were $30 \mathrm{~mm}$ $\mathrm{Hg}$ and 2.1 Wood units, respectively; the arterial blood gas analysis using a $1 \mathrm{~L}$ cannula showed $\mathrm{pH}$ 7.42, $\mathrm{PCO}_{2} 49.0 \mathrm{~mm} \mathrm{Hg}, \mathrm{PO}_{2} 102.0 \mathrm{~mm} \mathrm{Hg}$ and $\mathrm{HCO}_{3} 31.8 \mathrm{mEg} / \mathrm{L}$.

After 6 months of treatment, her weight had decreased by approximately $20 \mathrm{~kg}$, her congestive heart failure had improved and radiographs showed improvement in cardiac enlargement (figure 1B).

Normalisation of brain natriuretic peptide level and a mild increase in lung capacity were observed, and she recovered without significant deterioration in daily activities.

Initially, the patient was considered to have congenital hypoplasia of the right lung because contrast-enhanced CT of the chest revealed right pulmonary artery hypoplasia. The right lung was not expected to be capable of expanding due to long-term hernia compression.

Since the patient was in good general condition, surgical repair was decided to prevent future complications. Since the right colon, whole small intestines, and right kidney were in the thoracic cavity, open surgical repair was opted instead of minimally invasive laparoscopic repair. The surgery

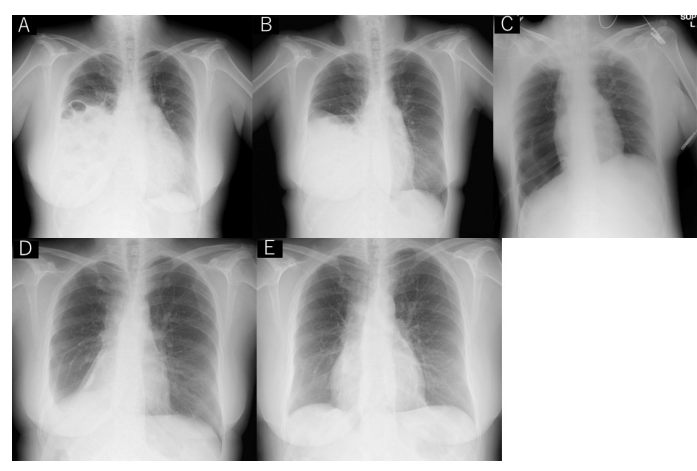

Figure 1 Radiographs of the chest. (A) Admission to our hospital. Elevation of the right diaphragm, intrathoracic intestinal prolapse with colonic gas and cardiac enlargement. (B) Following intensive treatment (6 months later). Mild expansion of the right lung, with improvement in cardiac enlargement. (C) Postoperative plain anteroposterior radiographs of the chest. In some cases of lung inflation, a small postoperative pneumothorax was observed. No herniated content was observed in the right thorax. (D) Follow-up at 2 months. Complete expansion of the right lower lung field had not been achieved, and there is pleural effusion. (E) After the introduction of non-invasive ventilation (NIV). Lung expansion was observed with positive pressure management via NIV.

was completed using mesh repair of the defective diaphragm.

After the surgical operation, radiographs revealed that the compressed right lung could be expanded, although complete expansion was not possible (figure 1C,D).

After 2 months, increased expansion of the compressed lung could be achieved using positive pressure from a home non-invasive ventilator (figure 1E).

For your reference, here, we presented the CT at the initial admission.

The patient's CT showed that diaphragmatic elevation, prolapse of intra-abdominal organs into the right thoracic space and collapse of the right lung due to compression caused by Bochdalek hernia (figure 2A-F). The background of these changes had associated with hypoxia with hypercapnia, chronic heart failure and secondary pulmonary hypertension.

After the surgical repair, the patient's lung function further improved, and lung perfusion 


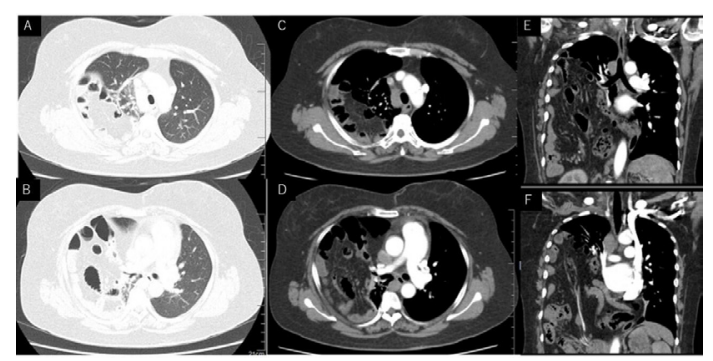

Figure 2 Contrast-enhanced CT at the admission to our hospital. $(A, B)$ Lung window: The right diaphragm is deficient on the right side posteriorly, and the gastrointestinal tract has prolapsed into the thoracic space and is highly elevated. Hypoplastic and poorly inflated lung due to hernia pressure is observed. In particular, the right lower lobe shows normal minimal inflation. $(C, D)$ Mediastinal window: The right pulmonary artery is slightly thin due to pulmonary hypoplasia, and the left pulmonary artery is dilated due to pulmonary hypertension. $(E, F)$ Coronal view: The entire small intestine, right ascending colon and right kidney have prolapsed into the thoracic space. The superior mesenteric artery is dilated and tortuous due to developed collateral blood vessels.

scintigraphy (figure $3 \mathrm{~A}, \mathrm{~B}$ ) revealed that the blood flow imbalance improved with the expanding lung volume.

Therefore, we could obtain a good prognosis, and the residual pulmonary hypertension also improved, as observed during postoperative right heart catheter examination.

Congenital diaphragmatic hernias can present in the early postnatal period or during infancy and are associated with significant morbidity and mortality due to pulmonary hypoplasia, pulmonary hypertension, and heart failure. Contrarily, symptomatic congenital Bochdalek hernia presenting in adulthood is extremely rare, with a prevalence of $0.17 \%-6 \%$ of all
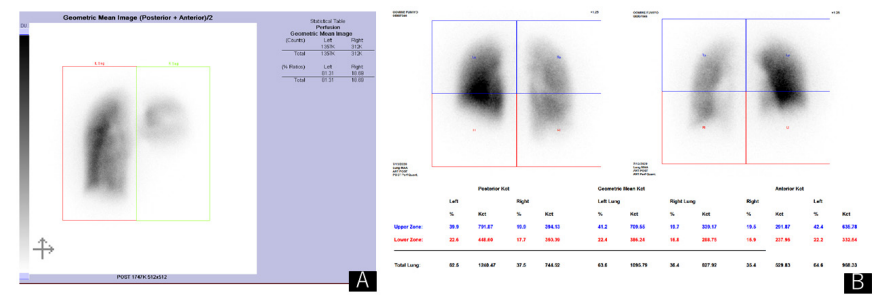

Figure 3 Tc-99m macroaggregated albumin lung perfusion scintigraphy. (A) Preoperative state: Right lung inflation due to right diaphragmatic elevation and decreased right lung blood flow (right side perfusion: $18.69 \%$, left side perfusion: $81.31 \%$ ). (B) Postoperative state: Adequate inflation of the right lung and the improvement of right pulmonary blood flow are observed (right side perfusion: $36.4 \%$, left side perfusion: $63.6 \%$ ). diaphragmatic hernias. ${ }^{1}$ Respiratory symptoms usually include dyspnoea and chest pain, and pulmonary hypertension has been reported in very rare cases. ${ }^{2}$

Lung and pulmonary vascular bed hypoplasia have been proposed as mechanisms that cause deficient gas exchange and persistent pulmonary hypertension. ${ }^{2}$

We initially considered that the collapsed lung would be unable to expand postoperatively because there has been no report of the re-expansion of the collapsed lung following surgery. ${ }^{3}$

To our knowledge, this is the first report of the achievement of hypoplastic lung re-expansion by aggressive positive pressure ventilation using a home non-invasive ventilator. Further, the pulmonary hypertension was resolved following surgical repair.

\section{Learning points}

- Bochdalek hernias comprise $0.17 \%-6 \%$ of all diaphragmatic hernias. It is extremely rare for an individual with Bochdalek hernia to grow into adulthood asymptomatically.

- Severe cardiopulmonary depression, such as congestive heart failure, secondary pulmonary hypertension and hypoxia with hypercapnia, was induced due to progressive compression of the lung by the hernia.

- The lung was not sufficiently expanded after surgery; however, re-expansion of the hypoplastic lung was achieved by aggressive positive pressure ventilation using a home non-invasive ventilator, and the pulmonary hypertension was resolved following surgical repair.

Acknowledgements The authors thank Editage (https://www.editage.jp/) for English language editing.

Contributors MS, TK and KK managed the patient. MS wrote the manuscript. $\mathrm{MH}$ reviewed and supervised the manuscript. All authors contributed to writing the manuscript. All authors have approved the version of the manuscript submitted for publication.

Funding The authors have not declared a specific grant for this research from any funding agency in the public, commercial or not-for-profit sectors.

Competing interests None declared.

Patient consent for publication Obtained.

Provenance and peer review Not commissioned; externally peer reviewed.

\section{ORCID iD}

Manabu Suzuki http://orcid.org/0000-0001-8515-6466

\section{REFERENCES}

1 Amer K. Thoracoscopic approach to congenital diaphragmatic hernias in adults: Southampton approach and review of the literature. J Vis Surg 2017;3:176.

2 Dobarro D, Schreiber BE, Haddock J, et al. Bochdalek hernia causing pulmonary hypertension. Circulation 2013;127:1837-9.

3 Akita M, Yamasaki N, Miyake T, et al. Bochdalek hernia in an adult: two case reports and a review of perioperative cardiopulmonary complications. Surg Case Rep 2020;6:72. 
Copyright 2021 BMJ Publishing Group. All rights reserved. For permission to reuse any of this content visit https://www.bmj.com/company/products-services/rights-and-licensing/permissions/

BMJ Case Report Fellows may re-use this article for personal use and teaching without any further permission.

Become a Fellow of BMJ Case Reports today and you can:

- Submit as many cases as you like

- Enjoy fast sympathetic peer review and rapid publication of accepted articles

Access all the published articles

Re-use any of the published material for personal use and teaching without further permission

Customer Service

If you have any further queries about your subscription, please contact our customer services team on +44 (0) 2071111105 or via email at support@bmj.com.

Visit casereports.bmj.com for more articles like this and to become a Fellow 